\title{
The difficulties experienced during the preparation and administration of oral drugs by parents at home: a cross-sectional study from Palestine
}

\author{
Ra'fat Ali', Abdullah Shadeed ${ }^{1}$, Hasan Fitian ${ }^{1}$ and Sa'ed H. Zyoud ${ }^{2,3,4^{*}}$ (D)
}

\begin{abstract}
Background: Failure to properly administer drugs to children at home may cause adverse events, which makes it a challenging job for parents or caregivers. The main goal of this study was to investigate the problems and difficulties that parents or caregivers faced when administering oral drugs to their children at home.

Methods: A cross-sectional study was conducted using a questionnaire consisting of 'yes/no' and multipleresponse questions to assess parents' experiences and problems with administering medication to their children at home. Data was collected from parents who visited primary health care centres in Nablus. Descriptive analysis was conducted to describe the characteristics of the sample.

Results: We interviewed 420 parents. $91.9 \%$ of the parents used drugs without prescription from a doctor, and the most commonly used non-prescription medicines were antipyretics ( $n=386,100 \%)$, influenza drugs $(n=142,36.8 \%)$, cough drugs $(n=109,28.2 \%)$ and antibiotics ( $n=102,26.4 \%)$. The study showed that $21.7 \%$ of parents used teaspoon and $7.1 \%$ used tablespoon in administering liquid medications to their children. When the children refused taking liquid medications, almost two-thirds of the parents (65.7\%) insisted their children take them, 21.5\% mixed it with juice, $5.2 \%$ mixed it with food and $4.7 \%$ mixed it with milk. $12.4 \%$ of the parents reported that they gave drugs in doses higher than prescribed by the doctor to treat their children more quickly. Also, our study revealed that $80.5 \%$ of the parents gave medications at incorrect intervals.

Conclusions: This study has shown that there is a proportion of caregivers or parents who administer oral drugs to their children incorrectly, which may involve giving them at the wrong intervals or doses, using incorrect instruments, or mixing them with food, juice or milk. The development of educational programs that will provide parents with education about medication administration is therefore recommended.
\end{abstract}

Keywords: parents, oral medications, administration, children

\footnotetext{
* Correspondence: saedzyoud@yahoo.com; saedzyoud@najah.edu

${ }^{2}$ Poison Control and Drug Information Center (PCDIC), College of Medicine and Health Sciences, An-Najah National University, Nablus 44839, Palestine ${ }^{3}$ Department of Clinical and Community Pharmacy, College of Medicine and Health Sciences, An-Najah National University, Nablus 44839, Palestine

Full list of author information is available at the end of the article
}

(c) The Author(s). 2020 Open Access This article is licensed under a Creative Commons Attribution 4.0 International License, which permits use, sharing, adaptation, distribution and reproduction in any medium or format, as long as you give appropriate credit to the original author(s) and the source, provide a link to the Creative Commons licence, and indicate if changes were made. The images or other third party material in this article are included in the article's Creative Commons licence, unless indicated otherwise in a credit line to the material. If material is not included in the article's Creative Commons licence and your intended use is not permitted by statutory regulation or exceeds the permitted use, you will need to obtain permission directly from the copyright holder. To view a copy of this licence, visit http://creativecommons.org/licenses/by/4.0/ The Creative Commons Public Domain Dedication waiver (http//creativecommons.org/publicdomain/zero/1.0/) applies to the data made available in this article, unless otherwise stated in a credit line to the data. 


\section{Background}

The administration of drugs at home may result in errors for the children, made by parents or caregivers, and may occur during administration, or by giving the drugs in the incorrect intervals or doses $[1,2]$. The proper administration of drugs requires the calculation of correct doses based on the weight of the child, using the right instruments, slow administration, and respect for the powder weight of drugs [3-5]. Failure to implement these conditions could cause adverse events [6]. Nonprescription or over-the-counter (OTC) drugs have also become excessively widespread in recent years, and have become major issues in children's health [7-10]. Lack of parental education and poor counselling or pharmacists' inadequate knowledge and confidence make incorrect administration and drug errors more common in developing countries, because outpatient clinics are very crowded and parents or caregivers are not well educated about health $[11,12]$.

Most currently available solid dosage forms cannot be used as produced in children under the age of 6-7 years, and the need to change dosage forms and dosing presents additional challenges for the pharmacist in the dispensing [13]. To our knowledge, several studies have been conducted among parents [14-18], considering aspects other than the difficulties that the parents experienced in administrating oral medications to their children. Parental difficulties in administering oral medications to their children were not assessed by any of these studies, however, or any other study conducted in Palestine. This study is thus the first conducted in Palestine to evaluate that issue. Medication efficacy may be altered by the use of inappropriate techniques used by the parents to overcome their children's' difficulties in swallowing oral medications. Acetaminophen is well established for safe use in children, and the risk of toxic reactions in children is less than in adults, and when it does happen it is mostly due to intentional overdoses $[19,20]$. On the other hand, the under-dosing of acetaminophen in pediatric patients with fever may prolong their condition [18]. Oral liquid medications are commonly given by teaspoon, the capacity of which can range from $1.5 \mathrm{ml}$ to $9 \mathrm{ml}$, leading to dosing errors with the subsequent complications. Little information about using self-therapy antibiotics in children in developing countries is available, despite the high rate of antibiotic resistance.

The health profile for Palestinian children keeps the issues facing the world in the 21st century in microcosm including migration, poverty, conflict, environmental degradation, and inadequate access to health care [21]. Therefore, this study was undertaken mainly to investigate the difficulties experienced by a sample of the Palestinian population in administering oral medications to their children at home. It is hoped that this research will contribute to a deeper understanding of this problem for many reasons. Some medication administration errors are life-threatening, as noted above. The use of the incorrect tools to administer medication leads to incorrect doses which have bad consequences on children's health. This study will provide a good foundation for further studies in this field. Healthcare providers are encouraged to educate patients about the correct techniques to overcome medication swallowing difficulties. Baseline data will be available from this study for educational purposes.

\section{Methods}

\section{Study design and setting}

This study was designed as a cross-sectional study. The study was conducted in the primary care centres in Nablus. Nablus city was chosen as it is one of the largest cities in Palestine. The data was collected over a period of 3 months from June 2018 to 31 to August 2018.

\section{Participants}

The subjects of our study were selected from people who visited the children care clinic in the primary care centers in Nablus where parents routinely went to vaccinate their children and thus where we concentrated on the dates when the appropriate sample could be recruited. The samples were selected by convenience with inclusion criteria of parents aged more than 19, who had a child or more aged between 6 months and 10 years [22-25], and who agreed to participate in the study. Subjects with vision problems, cognitive/physical disabilities, and caregivers other than parents were excluded. Convenience sampling was used. A total of 434 parents were approached; however, we got a consent from 420 parents with a valid response of $96.8 \%$.

\section{Intervention (questionnaire)}

The data was collected using a data collection questionnaire based on the relevant literature [11, 26-28]. The data collection form included four sections (Additional file 1).

The first section gathered demographic information including sex, residency, age, occupational status, marital status, educational level, monthly income and number of children between six months and ten years. The second section gathered information about drugs, including questions about who is responsible for administering medication at home, whether their child had ever refused to take tablets/pills, what was done when their child did not like taking tablet drugs, whether the treatment process failed because their child did not like taking tablet drugs, whether their child ever refused to take liquid medications, what was done when their child did 
not like taking liquid drugs, whether the treatment process failed because their child did not like taking liquid medications and the source of information for drugs given to their child.

The third section gathered information about the child, including questions about whether the child had difficulties in swallowing medication, the type of swallowing problem, how many times they complained about swallowing difficulties, whether swallowing difficulties were discussed with a doctor, and the doctor's recommendations.

The fourth section gathered information about practices, including questions about the tool had you used for giving a child their prescribed liquid medications, whether the leaflet attached to the drug was read, whether the child was given a dose higher than that prescribed to treat them more quickly, whether the child was given more than one type of oral medication at the same time, whether the child was given medications without prescription from a doctor, the type of medications used, whether the time the drugs were given to the child were recorded, and what was done with any remaining drugs when the child had recovered. They were also asked for the hours at which they would give their child medicine if it had been prescribed for three times a day.

A pilot study was undertaken with 30 parents to check for necessary modifications in the questionnaire, but as the selected parents all understood the questionnaire, no modifications were made. The questionnaire was reviewed and evaluated by experts in the field of pharmacy practice to ensure its content validity.

\section{Outcomes}

The primary outcome of our study was a composite consisted of parents' practices during the administration of oral drugs to their children at home and the acceptance behaviors of their children. In addition, swallowing problems during the administration of these drugs were included in the composite outcome. As a secondary outcome, we reported the most commonly used selftherapies by parents for their children.

\section{Sample size}

An online Raosoft sample size calculator (http://www. raosoft.com/samplesize.html( was applied to determine the sample size, which was 377. By assuming a response distribution for parents or caregivers who faced problems and difficulties when administering oral drugs to their children at home was 50\%. A confidence level of $95 \%$ and a $5 \%$ margin of error were used, adding a nonresponse rate of $10 \%$ to increase accuracy.

\section{Statistics}

The data was coded, categorised, and entered into the Statistical Package for the Social Sciences (SPSS), version 16.0. Descriptive statistics (e.g. frequency, percentage, mean, standard deviation) were used to illustrate the sociodemographic data and clinical data.

\section{Ethics}

Ethical approval for the study was obtained from institutional review board (IRB) at An-Najah National University. The questionnaire content was described before the interview, and verbal informed consent was taken from each parent before the interviews were started.

\section{Results}

\section{Sample characteristics}

A total of 420 parents completed the survey giving a valid response rate of $96.8 \%$. Table 1 provides the demographic information of the parents of our study. The mean age of parents was 30.2 with a standard deviation of 5.96; and the average number of children between 6 months and 10 years for each participant was 2.04 with a standard deviation of 0.98 . Mothers constituted the majority of the parents (98.8\%), most parents (86.4\%) lived in the city, and (59.8\%) had university education or higher. The majority of the parents had an income between 2000 and 4999 Shekels.

\section{Oral drug administration at home and acceptance behaviors of children}

Ninety-three point three percent of those responsible for drug administration at home were mothers (Table 2). When asked about the acceptance behaviour of their children during oral medication administration, over half of those surveyed reported that they didn't try to give their children tablets, sixty-four point two percent of those who had tried to do so reported that their children did not like taking tablet drugs (Table 2). When the children did not like taking tablet drugs, thirty-six point eight percent of the parents persuaded their children to drink more water, thirty-one point one percent requested another form of the drug and 30.2\% crushed the capsule (Table 2).

All parents reported that they tried liquid medications, fifty-five point five percent reported that their children refused to take liquid medications, and when the child did not like taking liquid medications, almost two-thirds of the parents $(65.7 \%)$ insisted their children take it anyway, twenty-four point five percent persuaded them to drink it with more water and $21.5 \%$ mixed it with juice (Table 2). There was a delay in treatment in $48.1 \%$ when the children did not like taking capsules or tablets, whereas it was $40.8 \%$ among those did not like taking liquid drugs. 
Table 1 Demographic information of parents $(N=420)$

\begin{tabular}{|c|c|c|}
\hline Characteristics & Item & Number (\%) \\
\hline \multirow[t]{2}{*}{ Gender } & Male & $5(1.2)$ \\
\hline & Female & $415(98.8)$ \\
\hline \multirow[t]{6}{*}{ Age } & $<25$ & $74(17.6)$ \\
\hline & $25-29$ & $135(32)$ \\
\hline & $30-34$ & $107(25.5)$ \\
\hline & $35-39$ & $73(17.4)$ \\
\hline & $40-44$ & $24(5.7)$ \\
\hline & $>45$ & $7(1.7)$ \\
\hline \multirow[t]{3}{*}{ Residency } & City & $363(86.4)$ \\
\hline & Village & $48(11.4)$ \\
\hline & Palestinian refugee camp & $9(2.1)$ \\
\hline \multirow[t]{5}{*}{ Number of children aged between six months and ten years } & 1 child & $147(35)$ \\
\hline & 2 children & $147(35)$ \\
\hline & 3 children & $93(22.1)$ \\
\hline & 4 children & $27(6.4)$ \\
\hline & 5 children & $6(1.4)$ \\
\hline \multirow[t]{4}{*}{ Participant's educational level } & Not educated & $4(1)$ \\
\hline & Primary school & $24(5.7)$ \\
\hline & Secondary school & $141(33.60$ \\
\hline & University & $251(59.8)$ \\
\hline \multirow[t]{2}{*}{ Father employment ${ }^{a}$} & Employed & $406(96.7)$ \\
\hline & Non employed & $10(2.4)$ \\
\hline \multirow[t]{2}{*}{ Mother employment } & Employed & $83(19.8)$ \\
\hline & Non employed & $337(80.2)$ \\
\hline \multirow[t]{4}{*}{ Income level of the family ${ }^{b}$} & $<2000$ ILS & $102(24.3)$ \\
\hline & 2000-4999 ILS & $247(58.8)$ \\
\hline & 5000-9999 ILS & $56(13.3)$ \\
\hline & $>10000$ ILS & $15(3.6)$ \\
\hline \multirow[t]{3}{*}{ Health insurance } & Governmental & $219(52.1)$ \\
\hline & Private & $58(13.8)$ \\
\hline & No insurance & $143(34)$ \\
\hline
\end{tabular}

${ }^{\text {a }}$ There are 4 dead fathers

${ }^{b} 1$ Israeli Shekel (ILS) equals 0.27 US Dollar

As shown in Table 2, most parents (66.7\%) obtained information about the medication from their doctors, $51.4 \%$ from medical leaflets and $25.7 \%$ from pharmacists.

\section{Swallowing problems during the administration of oral medications}

Around $33.1 \%$ of those who were interviewed reported that their children had swallowing problems during the administration of oral medication, where vomiting was the most common one in $59 \%$ of the cases. Of those who reported swallowing problems, fifty-four percent discussed the problem with their doctor, who advised them to change the drug in most cases $(48 \%)$ or offered advice to overcome the problem (38.7\%); (Table 3).

Parents' practices during the administration of oral drugs Eighty-three point six percent of the parents used a syringe to administer oral liquid drugs; however, other tools were also used (Table 4). A minority of parents (12.4\%) reported that they gave drugs in doses higher than prescribed by the doctor to treat their children more quickly. Forty-five percent of parents reported that they gave two drugs by mouth at the same time. Almost twothirds of the parents (69\%) said that they disposed of the 
Table 2 Oral drug administration at home and acceptance behaviors of children $(N=420)$

\begin{tabular}{ll}
\hline Variable & Frequency (\%) \\
\hline The person responsible for drug administration at home? & $6(1.4)$ \\
Father & $392(93.3)$ \\
Mother & $21(5)$ \\
Father \& mother & $1(0.2)$ \\
Brother & \\
Did the child mind take oral pills? & $106(25.2)$ \\
Yes & $59(14)$ \\
No & $255(60.7)$ \\
Did not try it
\end{tabular}

What did they do when the child refused to take tablet drugs? ${ }^{\text {a }}$

$\begin{array}{ll}\text { Drink more water } & 39(36.8) \\ \text { Crush capsule } & 32(30.2) \\ \text { Open capsule } & 9(8.5) \\ \text { Break capsule } & 11(10.4) \\ \text { Change head position } & 6(5.7) \\ \text { Mix with food } & 8(7.5) \\ \text { Mix with milk } & 3(2.8) \\ \text { Dissolute in water or other drinks } & 32(30.2) \\ \text { Request another form } & 33(31.1) \\ \text { Stop drug } & 15(14.2) \\ \text { Give during sleep } & 3(2.8)\end{array}$

What did they do when the child refused to take liquid drugs? ${ }^{\mathrm{a}} \mathrm{c}$

$\begin{array}{ll}\text { Force child } & 153(65.7) \\ \text { Drink more water } & 57(24.5) \\ \text { Mix with milk } & 11(4.7) \\ \text { Mix with juice } & 50(21.5) \\ \text { Mix with food } & 12(5.2) \\ \text { Stop drug } & 26(11.2) \\ \text { Give during sleep } & 13(5.6) \\ \text { Source of information about drugs }{ }^{\text {a }} & \\ \text { Medical leaflet } & 216(51.4) \\ \text { Doctor } & 280(66.7) \\ \text { Nurse } & 5(1.2) \\ \text { Pharmacist } & 108(25.7) \\ \text { Ordinary people } & 11(2.6) \\ \text { Old experience } & 49(11.7) \\ \text { Internet } & 50(11.9)\end{array}$

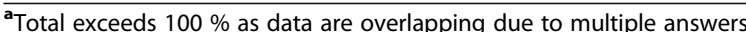
bPercentage was calculated by dividing by 106 " the number of children refused taking capsules"

'Percentage was calculated by dividing by 233 "the number of the children refused taking liquid drugs "

residual amount of the drug when the child was recovered, while $30 \%$ kept it for later use.

Surprisingly, ninety-one point nine percent of the parents used drugs without prescription from a doctor. The most commonly used self-therapies were antipyretics (n: $386,100 \%)$, influenza drugs $(\mathrm{n}=142,36.8 \%)$, cough drugs
Table 3 Swallowing problems influencing oral drug administration for managing childhood as reported by parents $(\mathrm{NO}=139)^{\mathbf{a}}$

\begin{tabular}{ll}
\hline Variable & Frequency (\%) \\
\hline Type of problem $^{\mathbf{b}}$ & \\
Drugs hang in the throat & $32(23)$ \\
Uncomfortable sense & $32(23)$ \\
Chocking sense & $18(12.9)$ \\
Cough & $32(23)$ \\
Vomiting & $82(59)$
\end{tabular}

How many times did he complain of swallowing difficulty?

$\begin{array}{ll}\text { Always } & 29(20.9) \\ \text { Sometimes } & 109(78.4) \\ \text { One time } & 1(0.7)\end{array}$

Doctor advise about the problem ${ }^{c}$

Change drug $36(48)$

Change dose 1 (1.3)

Give some tips to overcome the problem 29 (38.7)

Forget the problem 9(12)

aThe number (139) reflected the number of children who had swallowing problems

${ }^{\mathrm{b}}$ Total exceeds $100 \%$ as data are overlapping due to multiple answers

'Percentage calculated by dividing by 75 "the number of parents discussed swallowing problem with their doctor"

$(n=109,28.2 \%)$ and antibiotics (n: 102, 26.4\%); (Table 5). In the final part of the survey, the parents were asked about the interval that should be left between each dose when a drug prescribed to be given three times daily, and it was revealed that $80.5 \%$ administered medication incorrectly.

\section{Discussion}

This study analyses the difficulties and errors made by parents when administering oral medication to their children at home. Erroneous practices have been discovered through our study, such as the use of inappropriate tools to give medicine to children, the use of over-thecounter medications, the administration of medications at incorrect intervals, and incorrect practices when the child did not like taking oral drugs, such as mixing the drugs with food or opening tablets.

A child's adaptation to their drugs may be adversely affected by many factors, including the unpleasant taste [29], and this maladaptation could create difficulties for the parents when giving medications to their children. Around one-quarter of the parents in our study reported that their children did not like to take oral pills. Parents try to overcome the problem using many alternatives, such as mixing the drug with milk or with their children's favourite food or juice. In our study, $7.5 \%$ of the parents tried mixing tablets with food, and $5.2 \%$ tried mixing the liquid drug with food. Drug efficacy and food 
Table 4 Parents' practices during the administration of oral drugs $(N=420)$

\begin{tabular}{ll}
\hline Variable & Frequency (\%) \\
\hline A tool to give liquid drugs ${ }^{\mathbf{a}}$ & \\
Cup attached with drug & $39(9.3)$ \\
Teaspoon & $91(21.7)$ \\
Tablespoon & $30(7.1)$ \\
Syringe & $351(83.6)$ \\
Other tools & $4(1)$ \\
Reading leaflet & \\
Yes & $382(91)$ \\
No & $38(9)$ \\
Recording time when giving the drug & $228(54.3)$ \\
Yes & $192(45.7)$ \\
No & \\
\hline aTotal exceeds $100 \%$ as data are overlapping due to multiple answers
\end{tabular}

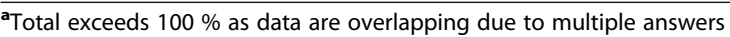

absorption may be reduced when mixing drugs with certain foods [30, 31]. Twenty-one point five percent of the parents in our study tried mixing liquid medicines with juice, which may have adverse effects on the absorption, bioavailability and serum concentrations of some medicines. Kane and Lipsky [32] conducted a study about grapefruit-drug interaction, and reported that the serum concentrations of some drugs, such as cyclosporine, tacrolimus, and carbamazepine, were elevated if they interacted with grapefruit juice; these drugs have severe side effects depending on the dose, so the alteration of serum concentrations due to interaction with grapefruit juice may have side effects.

In recent years, Israel has grown and produced several forms of citrus fruit, e.g. a pummelo-grapefruit hybrid, named Israeli Jaffa Sweetie [33]. As we know, Israel ensures its products have free access to the Palestinian market [34]. In addition, Palestine is the chief competitor of the United States for exporting grapefruit during the winter months [35]. The importance of focusing on this point is that Palestine is one of the major grapefruit producing countries in the Middle East, in addition to the great availability of grapefruit juices in the Palestinian market. A collection of 60 drugs or more was established to have side effects if taken at the same time as, or even many hours after, taking a small amount of grapefruit juice [36].

Thirty point two percent of the participating parents with children who did not like taking tablets crushed the capsules in order to administer them to their children. Treatment effectiveness can be altered when crushing tablets, which may alter the absorption of the drug, therefore increasing or decreasing its serum level, which may lead to serious side effects [37]. Compounding in pharmacies is a skill that is often expected of children to
Table 5 Types of self-therapies used by parents for their children $^{\mathbf{a}}(N=386)$

\begin{tabular}{ll}
\hline Variable & Frequency (\%) \\
\hline Antipyretics & $386(100)$ \\
Antibiotics & $102(26.4)$ \\
Antidiarrheal & $37(9.6)$ \\
Laxatives & $10(2.6)$ \\
Antiemetic & $17(4.4)$ \\
Cough drugs & $109(28.2)$ \\
Colic drugs & $59(15.3)$ \\
Creams & $56(15.5)$ \\
Influenza drugs & $142(36.8)$ \\
\hline
\end{tabular}

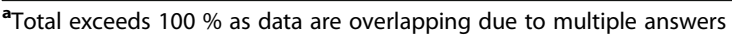

solve problems and difficulties that parents or caregivers faced when administering oral drugs to their children at home. This condition poses a range of additional obstacles, including stabilization, palatability, compensation, and compounding legislation [13]. In addition, manufacturers need to be supported to develop new pediatric drug delivery systems such as mini-tablets [38]. Such advances have the ability to turn children's drug administration into healthier, more effective and appropriate [39].

Dosing errors in children are common, because dosing for children needs to be assessed individually based on many factors, such as the patient's age and weight [40]. In this study, it was established that $21.7 \%$ of the participating parents used a teaspoon to give liquid medicine and $7.1 \%$ used a tablespoon, which may result in incorrect doses. Falagas et al [41] recommended that tablespoons and teaspoons should not be used due to their inaccuracy in dosing. In Palestine, sometimes, liquid drugs are not dispensed with a syringe or a quantitated cup so parents use spoons instead. In addition, $12.4 \%$ of the participating parents gave medicines with doses greater than that prescribed by the doctor in order to treat their children more quickly, which may in most cases lead to minor side effects, but also to hospitalisation or fatal side effects. Strenuous efforts are essential to prevent drug overdoses, which have recently become a leading cause of hospitalisation [42].

Surprisingly, when the participating parents were asked how to give a drug three times a day, only $19.5 \%$ know that it should be given every 8 hours, which means that the other $80.5 \%$ give the medications at incorrect intervals. Drug administration at incorrect intervals is a form of medication administration error. To ensure that serum drug levels are therapeutic, parents should administer drugs at the correct time [43].

This study has several limitations. The ability to generalise the study's results to all Palestinians is limited 
because it was conducted only in Nablus. Different areas of Palestine should therefore be included in future studies for more representative results. Secondly, certain phenomena, such as the effect of the researcher being present when answering questions, may result in biases which cannot be controlled. Thirdly, this is a cross sectional study and causal relationships between variables could not be established. Fourthly, the use of convenience sampling may have led to bias in the conclusions. Lastly, the lack of information about age of the child is a major limitation for the current study which is important to distinguish between drug-sophisticated children (children who take medication frequently or chronically) versus drug-naive children (children who take medication infrequently) as to swallowing difficulties as there is good data demonstrating differences in age of tolerability of solid dosage forms between these two populations.

\section{Conclusions}

This study has shown that there are a proportion of caregivers or parents who administer oral drugs to their children incorrectly, whether giving them at wrong intervals or doses, using incorrect instruments, or by administering non-prescription drugs. When children refuse to take their tablet or liquid medications, parents try to overcome the problem in many ways, such as mixing the drug with milk or with their children's favourite food or juice, or by crushing tablets. This study also established that parents give medicines in doses that are higher than those prescribed by the doctor in order to treat their children more quickly. Increased awareness about medication errors is needed by parents. The development of educational programs that will provide parents with education about the practice of medication administration is thus recommended. Also, it is recommended that when a doctor prescribe a drug to be given many times daily, he should write the intervals between doses in hours like ( $\mathrm{x}$ drug should be given every 8 hours not to write give it 3 times a day). The source of information about drugs should be the doctor and the pharmacist not the nurse, ordinary people, old experience or the internet. The last recommendation is that a law should be devised to force pharmacies not to dispense antibiotics unless prescribed by a doctor.

\section{Supplementary information}

Supplementary information accompanies this paper at https://doi.org/10. 1186/s12887-020-02105-w.

Additional file 1: Study questionnaires. This is the final English version of the questionnaire that was used to obtain data that helps to investigate the problems and difficulties that parents or caregivers faced when administering oral drugs to their children at home.

\section{Abbreviations}

IRB: Institutional Review Board; OTC: Over-the-counter; SPSS: Statistical Package for the Social Sciences

\section{Acknowledgments}

The authors would like to thank Palestinian Ministry of Health for providing the opportunity to conduct this study.

\section{Authors' contributions}

RA, and AS collected data, performed the analyses, conducted the literature search, and drafted the manuscript. HF coordinated, supervised, critically reviewed the manuscript; and interpreted the results. SZ conceptualised and designed the study; coordinated, supervised and analysed the data; critically reviewed the manuscript; interpreted the results and assisted in writing the final manuscript. All authors read and approved the final manuscript.

\section{Funding}

Not available.

\section{Availability of data and materials}

The datasets used for the current study are available from the corresponding author upon request.

\section{Ethics approval and consent to participate}

The IRB at An-Najah National University approved this study. Verbal informed consent was taken from each parent before the interviews were started. The study protocol was approved (including the verbal consent process) by the IRB and did not require written consent. Parents were informed that their information would be coded and anonymised.

\section{Consent for publication}

Not applicable.

\section{Competing interests}

The authors declare no conflict of interest. SZ is an Editorial Board member for the journal.

\section{Author details}

'Department of Medicine, College of Medicine and Health Sciences, An-Najah National University, Nablus 44839, Palestine. ${ }^{2}$ Poison Control and Drug Information Center (PCDIC), College of Medicine and Health Sciences, An-Najah National University, Nablus 44839, Palestine. ${ }^{3}$ Department of Clinical and Community Pharmacy, College of Medicine and Health Sciences, An-Najah National University, Nablus 44839, Palestine. ${ }^{4}$ Clinical Research Centre, An-Najah National University Hospital, Nablus 44839, Palestine.

Received: 15 November 2019 Accepted: 28 April 2020

Published online: 07 May 2020

\section{References}

1. Neuspiel DR, Taylor MM. Reducing the risk of harm from medication errors in children. Health Serv Insights. 2013;6:47-59.

2. Yin HS, Mendelsohn AL, Wolf MS, Parker RM, Fierman A, van Schaick L, Bazan IS, Kline MD, Dreyer BP. Parents' medication administration errors: role of dosing instruments and health literacy. Arch Pediatr Adolesc Med. 2010; 164(2):181-6.

3. Cram A, Breitkreutz J, Desset-Brethes S, Nunn T, Tuleu C. Challenges of developing palatable oral paediatric formulations. Int J Pharm. 2009; 365(1-2):1-3.

4. Adams LV, Craig SR, Mmbaga EJ, Naburi H, Lahey T, Nutt CT, Kisenge R, Noel GJ, Spielberg SP. Children's medicines in Tanzania: a national survey of administration practices and preferences. PLoS One. 2013:8(3):e58303.

5. Lopez FL, Ernest TB, Tuleu C, Gul MO. Formulation approaches to pediatric oral drug delivery: benefits and limitations of current platforms. Expert Opin Drug Deliv. 2015;12(11):1727-40.

6. Sammons HM, Choonara I. What is happening to improve drug therapy in children? Paediatrics Child Health. 2007;17(3):108-10.

7. Abraham O, Feathers A, Mook H, Korenoski A. The perceived benefits of student pharmacists educating children about over-the-counter medication safety. Curr Pharm Teach Learn. 2019;11(2):184-91. 
8. Krajnovic D, Ubavic S, Bogavac-Stanojevic N. Pharmacotherapy Literacy and Parental Practice in Use of Over-the-Counter Pediatric Medicines. Medicina (Kaunas). 2019;55:3.

9. Lovegrove MC, Weidle NJ, Budnitz DS. Ingestion of Over-the-Counter Liquid Medications: Emergency Department Visits by Children Aged Less Than 6 Years, 2012-2015. Am J Prev Med. 2019;56(2):288-92.

10. Wang GS, Reynolds KM, Banner W, Bond GR, Kauffman RE, Palmer RB, Paul IM, Rapp-Olsson M, Green JL, Dart RC. Medication Errors from Over-theCounter Cough and Cold Medications in Children. Acad Pediatr. 2020;20(3): 327-32.

11. Boztepe $\mathrm{H}$, Ozdemir $\mathrm{H}$, Karababa C, Yildiz O. Administration of oral medication by parents at home. J Clin Nurs. 2016;25(21-22):3345-53.

12. Ojha S, Choonara I. Medication errors in infants at home. Arch Dis Child. 2017;102(10):947-8.

13. Rieder M. Pharmacy and pediatric drug therapy: The key to safe and effective treatment for children. Am J Health Syst Pharm. 2019;76(19): 1452-3.

14. Al-Ramahi RJ, Zaid AA, Anabousi H. Problems associated with reconstitution, administration, and storage of antibiotic suspensions for pediatrics: a crosssectional study in Nablus city, Palestine. BMC Res Notes. 2015;8:760.

15. Markman S. Parental self-feeding effects on parental care levels and time allocation in Palestine sunbirds. PLoS One. 2014;9(12):e113890.

16. Zyoud SH, Abu Taha A, Araj KF, Abahri IA, Sawalha AF, Sweileh WM, Awang R, Al-Jabi SW. Parental knowledge, attitudes and practices regarding antibiotic use for acute upper respiratory tract infections in children: a crosssectional study in Palestine. BMC Pediatr. 2015;15:176.

17. Zyoud SH, Al-Jabi SW, Nabulsi MM, Tubaila MF, Sweileh WM, Awang R, Walsh A. The Validity and Reliability of the Parent Fever Management Scale: A Study from Palestine. Matern Child Health J. 2015;19(8):1890-7.

18. Zyoud SH, Al-Jabi SW, Sweileh WM, Nabulsi MM, Tubaila MF, Awang R, Sawalha AF. Beliefs and practices regarding childhood fever among parents: a cross-sectional study from Palestine. BMC Pediatr. 2013;13:66.

19. Zyoud SH, Al-Jabi SW, Sweileh WM. Worldwide research productivity of paracetamol (acetaminophen) poisoning: a bibliometric analysis (20032012). Hum Exp Toxicol. 2015;34(1):12-23.

20. Zyoud SH, Waring WS, Al-Jabi SW, Sweileh WM, Awang R. The 100 most influential publications in paracetamol poisoning treatment: a bibliometric analysis of human studies. Springerplus. 2016;5(1):1534

21. Waterston T, Nasser D. Access to healthcare for children in Palestine. BMJ Paediatr Open. 2017;1(1):e000115.

22. Mangione-Smith R, Zhou C, Robinson JD, Taylor JA, Elliott MN, Heritage J. Communication practices and antibiotic use for acute respiratory tract infections in children. Ann Fam Med. 2015;13(3):221-7.

23. Oria PA, Arunga G, Lebo E, Wong JM, Emukule G, Muthoka P, Otieno N, Mutonga D, Breiman RF, Katz MA. Assessing parents' knowledge and attitudes towards seasonal influenza vaccination of children before and after a seasonal influenza vaccination effectiveness study in low-income urban and rural Kenya, 2010-2011. BMC Public Health. 2013;13:391.

24. Marsh VM, Mutemi WM, Muturi J, Haaland A, Watkins WM, Otieno G, Marsh $K$. Changing home treatment of childhood fevers by training shop keepers in rural Kenya. Trop Med Int Health. 1999:4(5):383-9.

25. Kirby MJ, Ameh D, Bottomley C, Green C, Jawara M, Milligan PJ, Snell PC, Conway DJ, Lindsay SW. Effect of two different house screening interventions on exposure to malaria vectors and on anaemia in children in The Gambia: a randomised controlled trial. Lancet. 2009;374(9694):998-1009.

26. Boztepe $\mathrm{H}$, Ozdemir H, Karababa C, Yildiz O. Difficulties experienced during preparation and administration of oral drugs. Turk Pediatri Ars. 2014;49(3): 231-7.

27. You MA, Nam SM, Son YJ. Parental Experiences of Medication Administration to Children at Home and Understanding of Adverse Drug Events. J Nurs Res. 2015;23(3):189-96.

28. Tahaineh L, Wazaify M. Difficulties in swallowing oral medications in Jordan. Int J Clin Pharm. 2017:39(2):373-9.

29. Sharaideh R, Wazaify M, Albsoul-Younes AM. Knowledge and attitude of school children in Amman/Jordan toward the appropriate use of medicines: A cross-sectional study. Saudi Pharm J. 2013;21(1):25-33.

30. Otles S, Senturk A. Food and drug interactions: a general review. Acta Sci Pol Technol Aliment. 2014;13(1):89-102.

31. Zaid A, Abdallah Y, Zyoud SH. Knowledge, Attitudes, and Practices of Pharmacists Toward Splitting or Crush-ing Oral Solid Dosage Forms in
Palestine: Safety and Therapeutic Implications. Pal Med Pharm J. 2019;4(1): $11-26$.

32. Kane GC, Lipsky JJ. Drug-grapefruit juice interactions. Mayo Clin Proc. 2000; 75(9):933-42.

33. Gorinstein S, Caspi A, Libman I, Katrich E, Lerner HT, Trakhtenberg S. Fresh israeli jaffa sweetie juice consumption improves lipid metabolism and increases antioxidant capacity in hypercholesterolemic patients suffering from coronary artery disease: studies in vitro and in humans and positive changes in albumin and fibrinogen fractions. J Agric Food Chem. 2004; 52(16):5215-22.

34. Naqib FM. Economic aspects of the Palestinian-Israeli conflict: the collapse of the Oslo Accord. J Int Dev. 2003;15(4):499-512.

35. U. S. Foreign Agricultural Service. Foreign Crops and Markets. London: Forgotten Books; 1936

36. Bailey DG. Fruit juice inhibition of uptake transport: a new type of fooddrug interaction. Br J Clin Pharmacol. 2010;70(5):645-55.

37. Editorial Staff Prescrire International. Crushing tablets or opening capsules: many uncertainties, some established dangers. Prescrire Int. 2014;23(152): 209-11.

38. Gilpin A, Autmizguine J, Allakhverdi Z, Tessier JE, Giroux D, Lebel D, Litalien C. A Pan-Canadian Study on the Compounded Medicines Most in Need of Commercialized Oral Pediatric Formulations. Paediatr Child Health. 2018; 23(suppl_1):e53.

39. Hepburn CM, Gilpin A, Autmizguine J, Denburg A, Dupuis LL, Finkelstein Y, Gruenwoldt E, Ito S, Jong G, Lacaze-Masmonteil T, et al. Improving paediatric medications: A prescription for Canadian children and youth Paediatr Child Health. 2019;24(5):333-9.

40. Wong IC, Ghaleb MA, Franklin BD, Barber N. Incidence and nature of dosing errors in paediatric medications: a systematic review. Drug Saf. 2004;27(9): $661-70$.

41. Falagas ME, Vouloumanou EK, Plessa E, Peppas G, Rafailidis PI. Inaccuracies in dosing drugs with teaspoons and tablespoons. Int J Clin Pract. 2010;64(9): 1185-9.

42. Schillie SF, Shehab N, Thomas KE, Budnitz DS. Medication overdoses leading to emergency department visits among children. Am J Prev Med. 2009; 37(3):181-7.

43. Elliott M, Liu Y. The nine rights of medication administration: an overview. Br J Nurs. 2010;19(5):300-5.

\section{Publisher's Note}

Springer Nature remains neutral with regard to jurisdictional claims in published maps and institutional affiliations.

\section{Ready to submit your research? Choose BMC and benefit from:}

- fast, convenient online submission

- thorough peer review by experienced researchers in your field

- rapid publication on acceptance

- support for research data, including large and complex data types

- gold Open Access which fosters wider collaboration and increased citations

- maximum visibility for your research: over $100 \mathrm{M}$ website views per year

At $\mathrm{BMC}$, research is always in progress.

Learn more biomedcentral.com/submissions 